\title{
Y/DW-1851
}

\section{GRAND CHALLENGES OF ENTERPRISE INTEGRATION}

\author{
W. D. Brosey \\ Y-12 Technology Development \\ R. E. Neal \\ IMTI \\ D. Marks \\ Pinnacle Communication Services
}

April 2001

To be presented at:

$8^{\text {th }}$ IEEE International Conference on

Emerging Technologies and Factory Automation Antibes Juan-les-Pins, France

October 15-18, 2001

Prepared by the

Y-12 National Security Complex

P. O. Box 2009, Oak Ridge, Tennessee 37831-8169

managed by

BWXT Y-12, L.L.C.

for the

U.S. DEPARTMENT OF ENERGY under contract DE-AC05-00OR22800 


\section{DISCLAIMER}

This report was prepared as an account of work sponsored by an agency of the United States Government. Neither the United States Government nor any agency thereof, nor any of their employees, makes any warranty, express or implied, or assumes any legal liability or responsibility for the accuracy, completeness, or usefulness of any information, apparatus, product, or process disclosed, or represents that its use would not infringe privately owned rights. Reference herein to any specific commercial product, process, or service by trade name, trademark, manufacturer, or otherwise, does not necessarily constitute or imply its endorsement, recommendation, or favoring by the United States Government or any agency thereof. The views and opinions of authors expressed herein do not necessarily state or reflect those of the United States Government or any agency thereof.

\section{COPYRIGHT NOTICE}

"The submitted manuscript has been authored by a contractor of the U.S. Government under contract DE-AC05-00OR22800. Accordingly, the U.S. Government retains a paid-up, nonexclusive, irrevocable, worldwide license to publish or reproduce the published form of this contribution, prepare derivative works, distribute copies to the public, and perform publicly and display publicly, or allow others to do so, for U.S. Government purposes." 


\section{GRAND CHALLENGES OF ENTERPRISE INTEGRATION}

\section{William D. Brosey, BWXT Y-12 LLC}

Richard Neal, IMTI Inc.

Douglas Marks, Pinnacle Communication Services

Enterprise Integration connects and combines people, processes, systems, and technologies to ensure that the right people and the right processes have the right information and the right resources at the right time. A consensus roadmap for Technologies for Enterprise Integration was created as part of an industry/ government/ academia partnership in the Integrated Manufacturing Technology Initiative (IMTI). Two of the grand challenges identified by the roadmapping effort will be addressed here - Customer Responsive Enterprises and Totally Connected Enterprises. Each of these challenges is briefly discussed as to the current state of industry and the future vision as developed in the roadmap. 


\section{GRAND CHALLENGES OF ENTERPRISE INTEGRATION}

Enterprise Integration connects and combines people, processes, systems, and technologies to ensure that the right people and the right processes have the right information and the right resources at the right time. Enterprise Integration enables successful operation, in a world of continuous and largely unpredictable change, of a single manufacturing company or an everchanging set of extended (or "virtual") enterprises - by enabling quick and accurate decisions and adaptation of operations to respond to emerging threats and opportunities. A consensus roadmap for Technologies for Enterprise Integration was created as part of an industry/ government/ academia partnership in the Integrated Manufacturing Technology Initiative (IMTI). The manufacturing grand challenges addressed by the IMTI roadmaps were Lean, Efficient Enter-

prises; Customer Responsive Enterprises; Totally Connected Enterprises; Environmental Sustainability; Knowledge Management; and Technology Exploitation. Two of these grand challenges will be addressed here - Customer Responsive Enterprises and Totally Connected Enterprises. Each of these challenges is briefly discussed as to the current state of industry and the future vision as developed in the roadmap.

\section{CUSTOMER RESPONSIVE ENTERPRISES}

Future manufacturing enterprises will leverage a robust global communications infrastructure and customer-centric design, manufacturing, and life-cycle management systems to conceive, build, deliver, and support innovative products and services that directly satisfy diverse customers' needs and wants. 
The 1990s saw the dawn of the Age of the Delighted Customer. People can now surf the Internet from home and compare hundreds of products to find the best features and the best deal. This unprecedented market access, coupled with increased manufacturing quality, is raising the bar of competition like never before.

Whether the customer is an OEM or an end user, they are now firmly in the driver's seat. Product quality, long a discriminator, is becoming a non-factor. It's still important, but improvements in every industry mean that few defective products leave any factory.

Companies are finding it increasingly difficult to influence customers through advertising. With hundreds of channels and thousands of programs available on cable, satellite, and broadcast TV, plus competition from the Internet and the home PC, it's tough to get anyone's attention these days. Globalization of regional and national markets means that customers have more choices than ever.

Forward-looking companies recognized these trends in the early ' 90 s and began placing greater emphasis on delivering "customer satisfaction." The goal today is to establish a lifelong relationship with the customer - to earn their confidence that the company will always deliver a great product at a good price, support it well, and fix it if it isn't right.

A 1998 Deloitte \& Touche survey of 300 CEOs revealed that delivering value to customers is the highest priority of automotive companies. Other priorities included:

- Improving reliability of delivery

- Managing knowledge and innovation 
- Incorporating customer preferences early into new product development.

Just as information technology has delivered unprecedented power to individual consumers, it is also enabling manufacturers to establish personal relationships with every customer. Companies today have an increasing base of tools to assess customer satisfaction, solicit ideas for new and improved products, and market related products and services. The ability to capture and analyze demographics, buying habits, and customer feedback is helping companies make their products more useful and attractive than ever.

In the IMTI vision, advanced information management systems coupled with global communications networks with essentially limitless bandwidth, smart sensors and feedback mechanisms will enable manufacturers to continuously pulse their customers' needs and wants.

High-powered product and process design systems integrated into the global network will enable rapid iteration of product concepts and design options. Automated design advisors will put the customer in the loop to trade off cost, performance, features, and other attributes throughout the design phase. This will enable manufacturers and their customers to create the right product at the right price, delivered on time and within budget - the first time, every time.

The IMTI roadmaps target 24 critical "Nugget" capabilities - and corresponding R\&D goals, requirements, and tasks - that will enable manufacturers to meet the challenge of CustomerResponsive Enterprises. Following are highlights of several Nuggets that illustrate the depth of the IMTI vision and identify some of the enabling capabilities targeted for development by the IMTI plans. Further detail is provided in the individual roadmaps. 


\section{Customer/Requirements-Driven Manufacturing}

The Internet is making customer-responsive manufacturing a prerequisite for survival in industries large and small. Want to buy a new Jeep? A Donzi powerboat? A new Macintosh computer? Just log into the company's web site and you can pick out the product model you like, load it up with all the features you want, price it on the fly, and place your order.

At the next level, desktop videoconferencing, "shared whiteboards", and other collaboration applications are enabling customers and designers to exchange ideas and evaluate options in real time, irrespective of their physical locations.

When we think of customer-driven manufacturing, we might think of body scanning for customtailored clothes or using an interactive kiosk to select the desired features of a new car or house. While these are good examples, requirements-driven design is much more.

Conceiving a new product is not simple. If any of us could envision the next microwave oven, VCR, or other must-have product we would indeed be wealthy. There are many ways that products come about, but fulfilling customer desires is always the key to success.

Internet technologies are radically transforming the ways that companies and their customers interact to define and fulfill product needs and market opportunities. Requirements management tools are increasingly a part of that process for complex products, particularly those involving "systems of systems." From ordinary household chemical products to complex assembled systems, advanced software tools are helping define product attributes and manage requirements throughout the development process. 
In the IMTI vision, comprehensive detailed requirements iterated with the customer and captured in the enterprise's product realization system will drive design systems that use intelligent advisors and self-invoking analysis tools to systematically eliminate problems and design uncertainties en route to production.

While the process of innovation that brings forth new ideas must never be hindered, the exploitation of those ideas to deliver products that customers want will be greatly enhanced by requirements-driven manufacturing.

\section{Mature Electronic Commerce}

Mature electronic commerce? It's already here! Federal Express manages 100 million transactions a day. One million facilities have computer access to FedEx systems, and 650,000 communicate directly using FedEx software. Two-thirds of the transactions to which they respond are totally electronic.

Boeing, in partnership with its suppliers, has taken the position that e-commerce is the way that business is done. As a baseline, they adopted all-digital design for the 777 and its engines. As result, the GE90 engine for this aircraft had 70\% fewer hardware redesigns compared to their previous design, and essentially no rework at first assembly.

Since the use of disparate design systems presented problems, they worked with Pratt \& Whitney, Rolls-Royce, and GE to use STEP for product data exchange. This was a bold move, in light of the maturity of the STEP standards and tools. However, up to $90 \%$ of the designs trans- 
ferred successfully without intervention. All results are not yet in, but the partners agree that over $\$ 1$ million per year is saved just by not having to use common CAD systems.

Electronic commerce (EC) is revolutionizing the ability of customers to receive what they want, when they want it. Five years ago, purchasing specialists thumbed through dusty catalogs and wrote voluminous specifications to obtain vital materials and parts. A consumer looking for a new car simply walked the lots at the mercy of the dealer. Today, thanks to the Internet, businesses and consumers can shop with any source in the country to get what they want at the lowest price. With a click of a mouse, they can choose options and receive quotes with prices and delivery schedules.

How big is EC? The volume of business-to-business Internet commerce 7 years ago was negligible. In 1997, it was $\$ 5.6$ billion; in 1998 , it more than doubled to $\$ 16$ billion. By 2003 , it is predicted to be $\$ 400$ billion to $\$ 1$ trillion or more.

As EC becomes more pervasive, its impact on entire supply chains will only grow. This will increase pressure on the lower tiers of the chain to always be the best, and will create similar concerns for OEMs.

Already, many of the smaller manufacturers who serve as suppliers to Fortune 500 firms are being pressured to redefine relationships and transform their business process and systems to meet the EC needs and demands of their primes. For many, this transformation is the price of survival. 
Larger firms are redefining themselves as well to compete in the EC age. More and more, core manufacturing operations are being outsourced. Nike, for example is one of the world's largest shoe companies - but they do not own a single manufacturing facility. Similarly, "traditional" manufacturing companies such as Johnson Controls are evolving into product integrators, not just manufacturers. Johnson Controls no longer just makes car seats - it supplies custom interiors. This kind of integrated product approach provides stability in a chaotic business environment and stimulates a new level of excellence.

Growing pains aside, EC is a tremendous boon for both buyers and sellers. More companies are finding that on-line storefronts are increasing their market share and profit margins. Customers are increasingly pleased with the capability to quickly get the best deal and check order status on-line. GE, for example, purchased \$1 billion worth of parts over the Internet through its Trading Process Network in 1997.

Increasingly, the Internet is being used as a sounding board to gather data about customer desires for new products and feedback for improvements to existing products. At the same time, the Internet is accelerating shifts toward outsourcing. Manufacturing News reports that Fortune 500 companies already outsource $54 \%$ of their distribution and $46 \%$ of their manufacturing. The trend is accelerating, and the third-party logistics market is expected to double in 2 years, to $\$ 50$ billion.

In the IMTI vision, the Internet will evolve to become a unified global network handling all business transactions. Ultrafast communications will enable $100 \%$ accurate, high-speed transfer 
of terabytes of data. Advanced encryption techniques coupled with digital signatures and biometric identification devices will assure security of all transactions. All business systems financial, procurement, material control, etc. - will interface seamlessly using Internet-based protocols, enabling multiple companies to quickly team to create virtual enterprises able to develop, produce, and deliver new products with zero downtime and zero cost for integration.

\section{Mature Integrated Product \& Process Development}

By building an all-digital design and using modeling and simulation tools for product and process development, Chrysler saved over $\$ 800$ million on the design process for the new Jeep Grand Cherokee and delivered the first production unit in only 18 months.

By using virtual product development practices they were able to eliminate two build-and-test cycles, and thus save a year of development time. This also reduced risk for Chrysler's suppliers, which in turn reduced the suppliers' costs - by as much as $10 \%$ for expensive items such as the electrical system.

Customers want the best product that they can get at the lowest cost. While this sounds simple, the reality is that customer choices are based on a complicated tradeoff of appearance and style, functionality, availability, and perceived value as well as price.

The design of any product is based on balancing tradeoffs of cost, size, weight, durability, performance, material selection, complexity, producibility, time-to-market, resource availability, and similar factors. Concurrent engineering (CE) and integrated product and process develop- 
ment (IPPD) were conceived to replace the old way of doing business - the "throw it over the wall to the factory" approach. First, you designed a product; then you gave it to the shop to figure out how to make it. This process took decades for complex products such as military systems.

In CE and IPPD, the product and its processes are designed concurrently, drastically reducing time to market while tackling potential downstream issues on the front end. Although IPPD is not yet mature, companies are already seeking better answers. In recognition of the "need for speed," for example, companies such as Ford are declaring that even the current best practices of IPPD are too slow; they now demand "instant engineering."

Much attention is focused on the product design side of IPPD, and modeling and simulation tools have matured to the point that many of the design issues that once drove the iterative process of physical prototyping are now resolved in cyberspace. A leading-edge example is DARPA's Rapid Design Exploration and Optimization (RaDEO) program. RaDEO provides a design environment that features full immersion in virtual reality, interactive collaboration regardless of location, and real-time launch of analysis programs for evaluation of design options.

Modeling and simulation are also increasingly important in process development. However, in many companies concurrent engineering and IPPD still mean simply that manufacturing representatives consult with the design team. 
The Boeing 777 is an outstanding example of how modeling and simulation tools in an IPPD environment can reduce development cost and time. The 777 , the first jetliner designed entirely with 3D modeling technology, used techniques such as digital preassembly to eliminate the need for full-scale mockups, improve quality, and reduce changes and errors.

In the IMTI vision, mature IPPD means much more. It will provide the ability to quickly and accurately trade off all design considerations at every step of the product/process development process, in real time. It will also enable design changes to be rippled automatically to every affected point in the system. This will not only greatly reduce errors, but also enable fast, accurate corrective actions.

\section{TOTALLY CONNECTED ENTERPRISES}

Future manufacturing enterprises will be seamlessly interconnected among all their internal functions and external partners and stakeholders. This will enable integration of complex distributed supply webs and extended enterprises that interoperate as an integrated entity irrespective of geographic separation.

The days when a company could thrive with stand-alone systems for different enterprise function are fast disappearing. Marketing, engineering, production, finance, and support functions all must share data, models, and systems to compete and survive. Future enterprises also must be able to seamlessly connect with their suppliers and customers. 
Business and manufacturing systems may never become one, but they must share information to assure the total success of the enterprise. In the very near future, connectedness will be the rule, not the exception.

The pursuit of connectedness is pervasive:

- Enterprise resource planning (ERP) systems and packaged applications for multifunction operations are dominating the manufacturing business software market.

- Product data management (PDM) systems are also getting their share of attention. The market grew 27\% in 1998 and topped \$1.75 billion in 1999 .

- Although billions have been spent in improving inventory systems and turnover, $43 \%$ of U.S. firms say their inventory levels are the same or higher than 5 years ago, according to a survey by KPMG Peat Marwick and the University of Tennessee.

ERP and PDM systems are helping companies interconnect their diverse systems. That's the good news. On the other hand, in most cases ERM and PDM systems are not integrated with each other, and thus provide only a partial solution to enterprise integration needs.

These systems also require huge investments for acquisition and implementation, and rely on proprietary software that may not be compatible with emerging enterprise integration solutions based on open Internet protocols.

Much work remains to realize the totally integrated extended enterprise. In even the most welldeveloped supply chains, suppliers continue to use translators or even manual reentry to get basic 
product design data into their own CAD system. In many large companies, there is a significant gap between the information residing in the PDM and ERP systems. Except for bill-of-material data, sharing of product and process data among different functional systems is virtually nonexistent.

In the IMTI vision, a rich, transparently interconnected information infrastructure will enable different partners to interface their operations instantly regardless of functional differences or geographic distances. All enterprise knowledge assets will be mapped to a master enterprise model - a virtual framework mirroring every enterprise function and operation. Enterprise systems will "understand" their own functions and requirements, and be able to interoperate with diverse partners to enable a wide range of dynamic business relationships.

Such systems will radically reduce the cost, time, and resources needed to create products while simultaneously enhancing quality, reliability, and affordability.

The four IMTI roadmaps target some 25 critical "Nugget" capabilities - and corresponding R\&D goals, requirements, and tasks - that will enable manufacturers to meet the challenge of Totally Connected Enterprises.

Following are highlights of a few of these Nuggets that illustrate the depth of the IMTI vision and identify some of the enabling capabilities targeted by the IMTI plans. Further detail is provided in the individual roadmaps. 


\section{Integrated Product Realization}

The Technologies Enabling Agile Manufacturing (TEAM) program, a U.S. Department of Energy sponsored initiative, championed the vision of integrated product realization (IPR). TEAM demonstrated a new model for manufacturing that started with the definition of requirements and, using the Internet, managed the flow of information through each step - from concept design and optimization through detailed design, and to intelligent, closed-loop processing. TEAM delivered a toolset that supports IPR, and applied it. In demonstrations involving as many as 15 sites across the country, TEAM proved the effectiveness of the IPR model. Products produced in the demos included a cylinder head for a General Motors engine, an exhaust nozzle for a Pratt \& Whitney jet engine, and multiple components for national defense products. As one example of impact, the exhaust nozzle demonstration delivered a 6:1 reduction in design-tomanufacturing cycle time.

Simply put, integrated product realization (IPR) is all of the functions required to translate a defined need to a delivered product. Many forces in today's business environment are driving the need for IPR. First and foremost is cost. It is widely accepted that more than $70 \%$ of a product's cost is "locked in" at the design stage.

Once the design is complete, little can be done to impact the bottom line. The benefit of IPR in this area is that it embraces the entire product life cycle, from concept definition through manufacture, support, and disposal, enabling the ultimate life-cycle cost to be addressed from the inception of the design process. 
Disciplines such as design-to-cost and target costing are pieces of the puzzle - what IPR does is bring them together as part of a total solution to the cost equation.

Another driver of the need for IPR is life-cycle responsibility. Consumer preferences and environmental laws are continually increasing the pressure on manufacturers to provide for safe, environmentally benign recycle and disposal. In such an environment, it is critical that the systems for design, manufacturing, maintenance, and ultimate disposition of products be fully integrated. Kodak's disposable camera is an excellent example. The customer simply shoots the pictures, turns in the camera to be developed, and gets their pictures back while the used camera goes back to Kodak for refurbishment.

In the IMTI vision of the future, every attribute of a product will be captured in a single, highfidelity product and process model that resides in the enterprise's global dataspace. This model will contain or link to all information relative to the product, including physical geometry, materials of construction, physics/chemistry of function, manufacturing processes, support requirements, and recycle requirements.

The master product model will have the flexibility and detail to drive and support all actions relative to the product, from design, test, and manufacture to delivery, customer support, and eventual disposal. The model will interface with all enterprise applications and functions, providing the information they need for analysis, processing, correlation, manipulation, display, and other uses. 
Intelligent design systems linked to a rich base of science- and experience-based knowledge will enable products and processes to be conceived and optimized for total performance with little or no physical prototyping. These systems will interface seamlessly using a common dataset contained by the product model, ensuring $100 \%$ accurate data is instantly and continuously available to every system and application that needs it.

\section{Integrated Supply Chain Management}

The Automotive Industry Action Group launched the Manufacturing Assembly Pilot (MAP) to address supply chain information flow. They recognized that information exchange between an OEM and its first-tier suppliers is close to world-class, but that lower-tier suppliers must do "whatever it takes" to assure that parts reach the customer. By improving the integration of all supply chain members, the industry is:

- Reducing order processing from $\sim 4$ days to 1 hour.

- Reducing production planning from 5 days to 5 hours.

These improvements are being implemented throughout the automotive supply chain, and the major OEMs are working to define standards for supply chain management and integration. Through programs like this, supply chains can become totally connected.

Today's manufacturers increasingly depend on their suppliers to design, produce, distribute, and support products of increasing complexity. The largest manufacturers have thousands of suppliers, and even the smallest firms today rely on multiple tiers of supply. 
Supply chain management (SCM) is more critical than ever in an increasingly competitive marketplace. It is estimated that over $60 \%$ of a company's costs are tied directly to its supply chains, and critics argue - with some credibility - that as much as $50 \%$ of these costs are sheer waste and inefficiency.

In 1997, U.S. companies installed over $\$ 500$ million of SCM software. This has been a tremendous boon in "captive" relationships where a supplier does most of its business with a single prime manufacturer. However, current SCM systems are wildly disparate and uniformly incompatible, and few companies can afford to buy, operate, and support multiple systems. While Internet-based solutions are offering hope for the future, the current systems are not truly solving the problem.

In the IMTI vision of the future, enterprise connectivity will not only mean within the "four walls" of the company, but will extend across traditional enterprise boundaries. Processes and equipment will be connected not only to enterprise-wide systems, but also to the company's web of suppliers and partners.

A transparently interoperable, model-driven information infrastructure will enable partners to integrate operations instantly regardless of geographic distance and organizational, functional, and cultural differences. Different enterprises' systems will understand their relative functions and autonomously negotiate interfaces with other systems to share and act on critical data. This will efficiently enable a tremendous range of dynamic business relationships. 
The deep supply-chain connectivity envisioned by IMTI will enable full visibility into any part of the extended enterprise, all the while protecting the proprietary information of each partner. Mature electronic commerce will also be a key enabler to link the operations and systems of different partners. With mature EC in a totally connected enterprise, the Internet or its replacement will be the backbone and point of interface for virtually all manufacturing information.

\section{Coupled Business \& Operations Systems}

Lockheed Martin and its partners are demonstrating a new level of supply chain integration in the multi-billion-dollar AM3 (Affordable Multi-Missile Manufacturing) program. Using the Internet and commercial software, the AM3 consortium is integrating ERP systems from five companies to synchronize and optimize business and operations functions throughout the supply chain. They have also tightened integration within partner companies by replacing the master planning, material planning, production planning, and work control systems with an advanced planner and optimizer integrated with the ERP system.

The savings provided by this integration initiative are estimated at over $\$ 100$ million. Benefits include:

- Duration of a manufacturing lot for a complex assembly cut from 36 to 31 months

- Time to first delivery reduced $13 \%$

- Manufacturing throughput increased $17 \%$

- Manufacturing cycle time reduced $14 \%$.

Computing technology has powered tremendous progress in the streamlining of business systems and enhancement of manufacturing operations. However, in many companies these two func- 
tions still operate in isolation, relying on people to shuttle data from one domain to the other and respond to problems and action items in ad-hoc fashion.

In the IMTI vision, future business and operations systems will be seamlessly connected via a robust communications infrastructure that delivers the right information at the right time to the right decision-maker.

This coupling will extend far beyond just communications. Hierarchical, interconnected engineering, manufacturing, and business systems that all interface via the master enterprise model and knowledge base will ensure decisions are made with a firm understanding of other domains' needs and enterprise-wide impact.

These tightly coupled business and operations systems will provide managers, designers, and others with clear visibility into all enterprise functions and operations. Real-time status information about capacity, throughput, equipment utilization, quality performance, maintenance trends, resource inventories, and other barometers of factory/plant performance will be continuously fed into the enterprise knowledge base for ad-hoc access.

This will enable operators, supervisors, and managers to continuously pulse production performance, in turn enabling them to quickly recognize, isolate, and respond to problems. 
Continuous access to both live and historical data will also enable creation of highly accurate models and simulations of processes and operations. This in turn will enable confident prediction of the probable outcomes of contemplated changes and potential pitfalls.

With appropriate checks and balances, strategic and tactical decisions will instantly propagate changes to all parts of the enterprise and automatically update the living enterprise model. Development of new product and process designs, for example, will take into account all available resources and leverage the entire enterprise knowledge base to optimize desired attributes.

\section{Self-Integrating Systems}

We have limited versions of plug-and-play systems today. You can hook up a new peripheral or load a new application program into your desktop computer and be operational in a few minutes at most, guided by "smart" installer utilities that look at your hardware and software configuration and then guide you quickly through the setup process.

The Open Modular Architecture Controller (OMAC) group has the same goal for manufacturing controllers, and they are well on their way to reaching it. The group, led by General Motors and Boeing, is writing the specifications for a machine controller that will be PC-based and operate with standard protocols that enable both hardware and software modules to be transportable to any compliant controller and to operate in plug-and-play fashion - including the ability to selfintegrate into the manufacturing system. 
OMAC technology is expected to reduce control system design costs by over $15 \%$, acquisition by $30 \%$, implementation/operations by $10 \%$, and training by over $20 \%$. However, the real benefit will be the flexibility to operate in a totally connected enterprise.

Today, almost a third of a company's IT budget is spent on integrating applications so they can share data. This is a time-consuming, brute-force task. Manufacturers in the 21st century will not suffer this cost because systems will be designed from the ground up to interoperate with all other systems in the enterprise. In the IMTI vision, all manufacturing and business systems will be fully self-integrating - such that any new software or piece of equipment can be inserted into the system and be operational immediately, with zero integration cost or time.

Every product, process, business model, and system will "understand" its own behavior and input/output needs, such that when a new element is added to the system, it will automatically negotiate with all other elements of the system to fit in, with no human intervention.

Every manufacturing enterprise will operate from a dynamic base of knowledge that contains all the data required by any of its functions. From opportunity identification to production and eventual recycle of the product at its end of life, the system will guide the process. The monolithic and expensive ERP systems of today will be replaced by suites of inexpensive, best-inclass modules that simply plug into the enterprise information network.

Combining these self-integrating systems with shared knowledge bases and a robust communications infrastructure will enable widely distributed operations, systems, and processes to inter- 
act in real time, regardless of geographic separation. This will enable manufacturers to establish true "virtual extended enterprises" and flexible teaming relationships to pursue fast-breaking opportunities.

The challenges and visions that have been described represent only a small portion of the richness and depth of material available in the roadmaps that were developed and are now updated and maintained by IMTI. A growing partnership of industry, government and academia is working together to develop the roadmaps and the tools necessary to achieve manufacturing success in the $21^{\text {st }}$ century. 


\title{
GRAND CHALLENGES OF ENTERPRISE INTEGRATION
}

\author{
William D. Brosey, \\ BWXT Y-12 LLC, P.O. Box 2009, Bldg 9203, Oak Ridge, Tennessee 37831-8084 \\ Phone: (865) 574-0881 \\ FAX: (865) 576-2782 \\ Email: broseywd@y12.doe.gov \\ (Please send correspondence to William Brosey) \\ Richard E. Neal, \\ IMTI, 1315 West Bull Run Valley Road, Heiskell, Tennessee, 37754 \\ Phone: (865) 947-7000 \\ Fax: (865) 947-7001 \\ Email: imti1@msn.com \\ Douglas Marks, \\ Pinnacle Communication Services, 1440 Westchester Avenue, Winter Park, Florida, 32789-5535 \\ Phone: (407) 647-6564 \\ FAX: (407) 647-6564 \\ Email: dmarks1@cfl.rr.com
}

